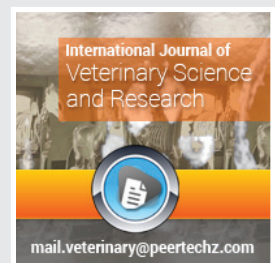

Life Sciences Group

\title{
International Journal of Veterinary Science and Research
}

Special Issue: Manual guidance of veterinary clinical practice and laboratory

\section{Abdisa Tagesu*}

Jimma University, School of Veterinary Medicine, Jimma, Oromia, Ethiopia

Received: 14 May, 2018

Accepted: 13 August, 2018

Published: 14 August, 2018

*Corresponding author: Abdisa Tagesu, Jimma University, School of Veterinary Medicine, Jimma, Oromia, Ethiopia, Tel: +251933681407,

E-mail: abdisatagesu@gmail.com

https://www, peertechz.com

The body condition of a livestock is generally assessed by visual observation. The references to an animal being too thin, in good flesh, or obese all relate to the animal's weight. Therefore, the weight of an animal can be used as a measurement tool to determine its well-being, or the presence of problems which may threaten the health of the horse. The weight of small animalsand poultry may be carried out by balance by automatic balance machine several methods can be used to determine the body weight of livestock in an approximate scale. Because of the variety of dosage forms in veterinary medicine and the diversity of animal and bird species treated, drug or dosage delivery sometimes requires the development of specific devices to ensure fast, safe, effective and low cost efficient treatment. The domestic animals body weight estimation equation as following [1].

*Equation of equine body weight estimation:

Weight $(\mathrm{kg})=\frac{\text { (girth measurement in } \mathrm{cm}) 2 \mathrm{x}(\text { length measurement in } \mathrm{cm})}{11,900}$

*Equation of Bovine body weight estimation:

Live weight in lbs.' $=\frac{\text { Length } \mathrm{x} \text { Girth square }}{300}$

Ibs = pound. $1 \mathrm{Ibs}=0.454 \mathrm{Kg} ; 1$ Inches $=2.54 \mathrm{~cm}$.

Formulations of Drug Dosage Forms of Animals are listed as following 2 .

Oral dosage forms: Refers to administration of drug through the mouth. The most commonly used preparations are solid oral dosage forms such as tablets, capsules, granules, powder, paste and boluses.

Parentral dosage forms: The most common parenteral dosage forms are stable aqueous solutions and subcutaneous implants.

\section{External dosage forms:}

$\checkmark$ Ointment- semisolid preparation for external application. $\checkmark$ Cream- a viscous semisolid, consisting of oil in water emulsion or water in oil emulsion.

$\checkmark \quad$ Dusting powder e.g., popular antibacterial agent applied on animal wounds.

$\checkmark$ Lotion- an aqueous solution or suspension for local application.

$\checkmark$ Spray-a drug applied in liquid form by pressure. forms: gaseous and volatile liquid anaesthetic agent (drugs), given by inhalation, e.g., Halothane.

Inhalation dosage forms: gaseous and volatile liquid anaesthetic agent (drugs), given by inhalation, e.g., Halothane.

\section{The Common Veterinary Drugs}

\section{Anthelmenthic drugs $[3,4]$}

Anthelmintics are drugs that are used to treat infections with parasitic worms. This includes both flat worms (flukes and tapeworms) and round worms (nematodes, round worms, whipworms, hookworms, pinworms, threadworms, and filarial worms). Anthelmentic can be classified into the following based on their mode of action: Nicotin agonist, acetyl cholinesterase inhibitor, GABA agonist, GluCl potentiator, calcium permeability increase, B-tubulin binding, proton ionophores, inhibitor of malate metabolism, inhibitor of phosphoglycerate kinase and mutase, and inhibitor of arachidonic acid. Base on spectrum of action, anthelmintics can be classified as: broad spectrum (kill a wide variety of worms) or narrow spectrum (kill one or two varieties).

Benzimidazole (albendazole, cabendazole, fenbendazole, flubendazole, mebendazole, oxfendazole, oxibendazole, parbendazole and triclabendazole). The benzimidazole bind to a specific building block called beta tubulin and prevent its incorporation into certain cellular structures called microbutbules, which are essential for energy metabolism. Then parasite will dieor paralyzed from action of benzimidazole 
drugs. It is broad spectrum in treatment of all nematode, cestode and adult form of fasciola. Triclabendazole is narrow spectrum for faciolosis, and also broad spectrum for fasciola species, which means it can kill all stages of fascioala (larva and adult stage).However, it is not recommended for pregnant animals due to its teratogenic effect.

Imidazothiazoles (tetramisole, levamisole): it is broad spectrum gainist nematodes. Levamisole is selectively as a cholinergic agonist at aynaptic and extra synaptic nicotinic acetylcholine receptors on nematode muscle cells. This cause spastic paralysis of susceptible nematode by selecting gating acetylene receptore ion channels on nerve muscle. Levamisole is a nematodicidal compound effective against lung and GI tract nematodes and annelid (leech) but not effective against cestode and trematode parasites, and it is not ovicidal. Levamisole have been shown to have immune modulatory effects, that is; it enhances immune responsiveness by restoring the number of $\mathrm{T}$ lymphocytes to normal when they are depleted. It is not used in horse because of its linmitedefficacy againstmany equine parasites.

Tetrahydropyrimidines (pyrantel, morantel and oxantel): These drugs act selectively as agonist at synaptic and post synaptic nicotinic acetylcholine receptors on nematode muscle cells and produce contraction and spastic paralysis. Pyrantel and morantel are 100 times more potent than acetylcholine, although slower in initiating contraction

Organophosphate Compounds (Haloxon, coumaphos, dichlorvos, crufomate and naphthalophos): Organophosphate inhibits many enzymes, especially acetyl cholinesterase, by phosphorylating their esterification site. This blocks cholinergic nerve transmission in the parasite, which results in spastic paralysis. Originally, they were used extensively as insecticides, then as ectoparasiticides. Dichlorvos is used as an anthelmintic in horses, pigs, dogs, and cats; trichlorfon in horses and dogs; and coumaphos, crufomate, haloxon, and naftalofos in ruminants. Haloxon is probably the safest organophosphate anthelmintics for use in ruminants

Piperazine (Diethylenediamine): The drug has good efficacy profiles against ascarid and nodular worm infections of all species of domestic animals, moderate for pinworm infections. Piperazine acts by blocking transmission by hyperpolarizing nerve membranes at the neuromuscular junction leading to parasite immobilization by flaccid paralysis and consequent removal from predilection site and death. Piperazine is a selective agonist of gamma-amino butyric acid (GABA) receptor resulting in opening of chloride channels and hyperpolarization of the membrane of the muscle cells of the nematode parasites. Mature worms are more susceptible to the action of piperazine than the younger stages.

Bunamide: It is effective against the common tapeworm species and it is most effective when given after fasting. It is formulated as tablets (hydrochloride salt) or suspension (hydroxynaftoate salt) for oral administration in companion animals and ruminants, respectively. It acts by disrupting the tapeworm`s tegument and reduces glucose intake, as a result, the subtegumental tissues are exposed and the worm destroyed by the host`s digestive enzymes.
Praziquatel: its mode of action is by increasing the cestode's cell membrane permeability; this disintegrates the worm's outer tissue covering.

Macrocyclic Lactones (abamectin, ivermectin, doramectin, eprinomectin, and selamectin): The macrolides act through selective toxic effects on insects, acarines, and nematodes. However, they do not possess efficacy against cestode and trematode parasites due to both trematode and cestode they haven't recetor for this ivermectin or lack of GABA receptor. The macrocyclic lactones induce reduction in motor activity and paralysis in both arthropods and nematodes. The parasitic effects are mediated through GABA and/or glutamate-gated chloride channels (GluCl), collectively known as ligand-gated chloride channels. The endectocides cause paralysis and death of both arthropod and nematode parasites due to their paralytic effects on the pharyngeal pump which affects nutrient ingestion, and on the parasite somatic musculature limiting its ability to remain at the site of predilection in the host.

\section{Anti-microbial and anti fungal [5-7]}

Antimicrobial therapy is based on the selective toxicity of a drug for invading organisms, i.e ability to kill or inhibit an invading microorganism without harming the cells of the host. Antimicrobial can be classified into different based on their action, they are like:

Inhibition of cell wall synthesis: penicillins, cephalosporins.

Impairment of cell membrane function: Polymyxin, tyrocidin, and the polyene antifungal agents, nystatin and amphotericin B that bind to cell-wall sterols.

Reversible inhibition of protein synthesis: Affect the function of 30 s or 50 s ribosomal subunits, and are bacteriostatic drugs which include chloramphenicol, tetracyclines, macrolides (erythromycin) and clindamycin.

Alteration of protein synthesis: Bind to the 30 s ribosomal subunit and affect cell membrane permeability which eventually leads to cell death, eg aminoglycosides (eg; streptomycin, gentamicin).

Inhibition of nucleic acid function or synthesis: Rifamycins (rifampin) which inhibit DNA-dependent RNA polymerase, and quinolones (oxolinic acid).

Interference with microbial metabolism: Sulphonamides, trimethoprim.

Inhibition of viral enzymes: These agents block the viral enzymes that are essential to DNA synthesis, thus halting viral replication, eg nucleic acid analogues (zidovudine, acyclovir, and vidarabine).

The most common bacteriocidal (kill bacteria) antimicrobials are like: Agents that alter microbial cell wall or membrane permeability are generally bactericidal. These include the penicillins, cephalosporins, aminoglycosides and polymyxins Essentially bacteriostatic agents inhibit bacterial protein synthesis, chloramphenicol, macrolides and tetracyclines. 
The importance of combination of two or more antimicrobial drugs useful in veterinary medicine, the importances of combining are:

* To overcome infection

* To avoid rapid emergence of resistant mutants, especially in prolonged therapy with drugs such as streptomycin which tend to induce rapid bacterial resistance

* To prevent inactivation of the antimicrobial agent by bacterial enzymes, eg, the use of co-amoxiclav, a combination of amoxycillin and clavulanic acid, an $\alpha$-lactamase inhibitor

* To achieve a synergistic effect, as is exemplified by cotrimazine, a combination of sulphadiazine and trimethoprim

* To reduce the severity or incidence of adverse reactions where the organisms are fully sensitive to each drug.

\section{Common veterinary antimicrobials [5-8]}

Pencillins (procaine pencilin, pencilin G): It is betalactames Penicillinswhich interfere with the synthesis of the bacterial cell wall peptidoglycan (the major constituent of $\mathrm{G}+\mathrm{ve}$ bacteria cell wall). After attachment to binding sites on bacteria, they inhibit the transpeptidase enzyme involved in cross linking of the peptidoglycan chain, the $3^{\text {rd }}$ and final stage of bacterial cell wall synthesis. It is narrow against $\mathrm{G}+\mathrm{ve}$ aerobes and anaerobes bacteria.

Cephalosporins: It is beta lactamase group, which have certain therapeutic advantages over penicillins which include their relative resistance to $\beta$-lactamase, their broad-spectrum of activity, their ability to reach the CNS, and less likelihood to cause allergic reactions, hence they are suitable for use in rabbits, guinea pigs, and reptiles. They inhibit the $\beta$ - lactambinding proteins involved in bacterial cell wall peptidoglycan synthesis, hence are bactericidal. Cephalosporin have four generation, they are like:

1. First-generation cephalosporins: cefadroxil, cefalexin, cefazolin, cephacetril, cephradine and cephaxazole)

2. Second-generation cephalosporins: cefaclor, cefamadole, cefmetazole, cefonicid, ceproxil, and loracarbef. Cephamycin; cefotetan and cefoxitin.

3. Third-generation cephalosporins: cefdinir, cefixime, cefoperazone, cefotaxime, ceftizoxime, and ceftriaxone.

4. Fourth-generation cephalosporins: Examples are cefepime and cefpirome. They have a wide antibacterial spectrum (Enterobacter, Escherichia, Klebsiella, Proteus, and Pseudomonas). Cefepime is highly resistant to $\beta$-lactamases.

Aminoglycosides (streptomycin, dihydrostreptomycin, neomycin, tobramycin, kanamycin, gentamicin, amikacin, netilmicin): They bind to the $30 \mathrm{~S}$ ribosome and inhibit the rate of bacterial protein synthesis and the functionality of mRNA translation, resulting in the synthesis of abnormal proteins.
Aminoglycosides alter cell membrane permeability causing nonspecific membrane toxicity. Their effect is bactericidal and is enhanced by agents that interfere with cell wall synthesis (eg, $\beta$-lactam antibiotics). They are effective against many aerobic G-ve and some G+ve organisms; Leptospira spp are also affected.

Teteracycline (Tetracycline, oxytetracycline, demeclocycline, doxycycline, methacycline, and minocycline): Tetracyclines are bacteriostatic; they inhibit microbial protein synthesis by binding to $30 \mathrm{~S}$ ribosome and block the attachment of aminoacyl tRNA to the mRNA-ribosome complex. As a result, they block the addition of amino acids to the growing peptide chain. It is broad spectrum against G+ve and G-ve bacteria, spirochaetes, rickettsiae (Anaplasma, Cowdria, and Ehrlichia species), mycoplasmae, chlamydiae, amoebae, and some protozoa (Theileria and Babesia species)

Strangles in horses; actinomycosis and actinobacillosis; anthrax; pasteurellosis; clostridial diseases; respiratory and urinary tract infections in dogs and cats; psittacosis in birds, rickettsial diseases; bovine anaplasmosis, caprine heartwater, canine ehrlichiosis, mycoplasma infections of poultry including borreliosis, coryza and erysipelas all respond to tetracycline therapy.

Chloramphenicol: Chloramphenicol binds with the 50 s ribosomal subunit to inhibit peptide bond formation and protein synthesis in the bacterial or disease causing organism. It is a broad-spectrum bacteriostatic agent active against many gram-positive and gram-negative bacteria, Rickettsia, Mycoplasmas, and Chylamydia. It has an excellent therapeutic activity against Salmonella.

Macrolide (oleandomycin, tylosin, carbomycin, spiramycin, tiamulin, tilmicosin): It inhibits bacterial protein synthesis by binding to the 50 s ribosome, preventing translocation of amino acids to the growing peptide. It is effective against gram positive organisms such as staphylococci, mycoplasma, spirochaetes, and certain mycobacteria are sensitive to the group.

Lincosamide: They are effective against gram-positive cocci, anareroes, and Toxoplasm and mycoplasma species.

Sulphonamides: It is broad spectrum antimicrobial drugs which inhibit bacteria and protozoa (coccidiosis). Long acting (sulphamethoxypyridazine, sulphamethoxine, sulphadoxine). Enteric or gut-activesulphonamides (Phythalylsulphathiazole, Succinyl sulphathiazole, Sulpha-bromethazine, Sulphaquinoxaline, Sulsalazine, Sulphacetamide). Being impermeable to folic acid, many bacteria must rely on their ability to synthesise folate from PABA. Pteridine and glutamate in contrast the mammalian in cells cannot synthesize folic acid and must obtain preformed folate as a vitamin in their diet. The sulphonamides are structurally similar to PABA, the sulphonamides competitively inhibit dihydropteroate synthetase, the enzyme that catalyses the incorporation of PABA into dihydrofolic acid.

The folic acid is required for pure and D.N.A synthesis which without it bacteria growth is inhibited. Sulphonamides have a broad- spectrum of activity against both gram- positive and gram negative bacteria, and some protozoa (coccidia, Neospora, Toxoplasm), riicketsiae. 


\section{Antifungal Drugs}

Fungal infections (mycoses) are classified into two types: topical (superficial), which affects the skin and mucous membranes, and systemic which affect areas as the blood, lungs, or C.N.S. The most common disease of fungas in domestic animals are rised from the strain of fungas like: Blastomycosis, Cryptococcosis, Histoplasmosis (epizootic lymphangitis) and Coccidioidomycosis. The most common drug available for treatment of fungal infections are like:

$\checkmark$ Superficial agents ( griseofulvin)Polyene macrolides (amphotericin B, nystatin)

$\checkmark$ Imidazole derivatives ( ketaconazole (the prototype), miconazole, clotrimazole,fluconazole, itraconazole, enilconazole, and terconazole)

$\checkmark$ Antimetabolites (5-flucytosine)

\section{Antiprotozal Drugs}

$\checkmark$ Anticoccidiosis: Sulphonamides, Quinazolines, Quinolones, Symmetrical triazinones and Thiamine antagonists

$\checkmark$ Antitypanosomiasis: Diamidines(Diminazene aceturate, Phenamidine, Stilbamidine and Pentamidine), Phenanthridines (phenidium, dimidium, homidium and isometamidium), Quinapyramine Compounds (quinapyramine chloride, quinapyramine sulphate and suramin), Organic arsenicals( melarsomin, or melarsoprol)

$\checkmark$ Antipiroplasmosis (amicarbalide isethionate, buparvquone, halfuginone, menoctone, parvaquone tetracycline, imidocarb, quinuronium sulphate). It can inhibit anaplasma like: anaplasmosis, babesiosis, cowdriosis, theileriosis, ehrlichriosis, and hepatozoonosis and in avian spirochaetosis.

\section{Analgesia and Anesthesia Drugs}

The most common drugs in surgery are used in preoperative, during surgery and post-surgery. General anesthesia is proceded by premedication with on eor more drugs. The importance of premedication drugs are

$\checkmark$ Reduce the amount of anaesthetic required (injectable and inhalant), so reducing side effects (and costs!)

$\checkmark$ Relax muscles

$\checkmark$ Provide analgesia

$\checkmark$ Provide sedation

$\checkmark$ Suppress vomit reflexes

$\checkmark \quad$ May help calm a stressed animal

$\checkmark \quad$ May help make the animal easier to handle

$\checkmark \quad$ Improve recovery (fewer tremors and less vocalising)

\section{Common premedication drugs}

Opioid drugs (Oxymorphone, Fentanyl, Morphine, and Butorphanol): Opioid produce their effect by binding three different receptors [mu $(\mu)$, kappa $(к)$, and delta $(\delta)]$ as either agonists, partial agonists or antagonists. The location of these receptors varies, but in general, resides within the brain and spinal cord. Providepotent analgesia; concurrent administration can lower the dose of inhalant or barbiturate general anesthetic for surgery; mechanism mediated by receptor binding in the brain and spinal cord; long history of use in research; reversible with Naloxone.

Alpha-2 agonists: It is used for their sedative and analgesic properties in a variety of species. Producesanalgesia of short duration; can be combined with Ketamine to produce adequate surgical anesthesia in many species; effects can be reversed with a subcutaneous $\alpha$ antagonistsinjectionsuch as Atipamezole.

Xylazine: it has potent sedative effect, but cardiovascular depression can be profound. The side effect of this drug is like: vomiting, diuresis, GIT motility depression, platelet aggregation.

Acepromazine maleate (Phenothiazine): It has tranquilliseraction which makes calm aggressive and apprehensive animals. The IV, IM, SC or oral dose may be used in the dog or cat. Doses: dogs: 0.01-0.1 mg/kg IV, intramuscularly (lM), subcutaneously (SC), $1-3 \mathrm{mg} / \mathrm{kg}$ oral; cats: $0.05-1.0 \mathrm{mg} / \mathrm{kg}$ IV, IM, SC, 1-3mg/ kg oral.

Atropine: It is parasympatholytic, blocking acetylcholine (ACh). It can increase the occurrence of cardiac dysrhythmias. The main uses of atropine now are to facilitate ophthalmic examination by dilating the pupil (mydriasis) or to treat or prevent certain types of bradycardiaor bradyarrhythmias. Atropine is used to decrease salivary and airway secretions during anaesthetics. Doses: dogs/cats: $0.02 \mathrm{mg} / \mathrm{kg} \mathrm{IV}, 0.045$ $\mathrm{mg} / \mathrm{kg}$ IM or SC

Diazepam: It has a sedative, tranquilliser, anticonvulsant, and skeletalmuscle relaxant and appetite stimulant actions in cats. When used alone, diazepam occasionally results in excitation rather than sedation, so it is most often used in combination with another sedative, usually ketamine. Dose: dogs/cats: $0.1-0.5 \mathrm{mg} / \mathrm{kg} \mathrm{IV}$

Medetomidine: It is alpha 2-adrenergic agonist, Good skeletal muscle relaxation; sedation and analgesia are induced by administration. Sedation is reversed by administration of atipamezole. Doses: dogs: 0.01-0.05 mg / kg IV, IM, SC; cats: 0.05-0.15 mg/kg IV, IM, SC

Nonstheroid anti-inflammatory drugs (meloxicam, carprofen, flunixin and ketoprofen) .It has about 13 different classes of drugs which share inhibitory activity of the cyclooxygenase (COX) enzyme. The COX enzyme facilitates the production of Prostaglandin G2 (PGG2) which then follows a variety of enzymatic processes in the production of several compounds that are involved in normal physiological processes and production of Prostaglandin E2 (PGE2). PGE2specifically play as role in the perception of pain in the periphery and within the central nervous system. Thus, blockade of PGE2by 
COX inhibition is effective in control of discomfort at the site of insult and within the central nervous system. Two forms of the COX enzyme have been well characterized (COX-1 and COX-2). As a result, COX inhibitors are often referenced as non-selective COX inhibitors or selective COX-2 inhibitors. This distinction has been made because inhibition of $\mathrm{COX}-2$ is believed to be the predominant method of NSAID function to provide analgesia and anti-inflammatory action even though this "consensus" is still under debate. Over the past 10 years, several NSAIDs have emerged for veterinary use that are COX-2 selective, such as Carprofen and Meloxicam which can be administered once every 12-24 hours in most species. Newer drugs (Carprofen, Meloxicam) include a long duration of analgesic activity; newer drugs demonstrate analgesic quality that rivals some opioids; not a DEA controlled substance; there are multi route administration methods for several NSAIDs; relative safety when administered at prescribed dosages

Alpha-2 antagonists (yohimbine): it is used as reversal agents for $\alpha_{2}$ agonists.Administration at the end of a procedure where the anesthetic combination included Xylazine or Medetomidine, $\alpha_{2}$ antagonist will aid in reducing anesthesia time and prompting anesthetic recovery.

\section{General anesthesia}

Ketamine: Ketamine is associated with increased muscle rigidity and excessive salivation. Ketamine may cause increased heart rate, cardiac output, and blood pressure. Ketamine is used in combination with other injectable agents such as $\alpha_{2}$ agonists or benzodiazepines to reduce or eliminate many of the less desirable side effects if used alone. Doses: dogs: $11-22 \mathrm{mg} / \mathrm{kg} \mathrm{IM}, \mathrm{IV}, \mathrm{SC}$; cats: $1.0-33 \mathrm{mg} / \mathrm{kg} \mathrm{IM}, \mathrm{SC}, \mathrm{IV}$. Ketamine + Diazepam: Both drugs can be mixed in a single syringe prior to administration. Advantages include limited cardiovascular effects including minimal hypotension as compared to Ketamine/Xylazine combinations. Ketamine + xylazine +acepromazine: increases the depth of anesthesia and substantially prolongs the duration of anesthesia as well as recovery time. The combination will produce less cardiovascular depression than xylazine-ketamine. Dose Diazepam 0.1-0.4 $\mathrm{mg} / \mathrm{kg}$ and ketamine $5 \mathrm{mg} / \mathrm{kg}$ given IV.

Barbiturates: Sodium Pentobarbital, Methohexital, Thiopental. Barbiturates function as GABA agonists and are considered to be good anesthetic agents but provide unreliable sedation at low dosages and inadequate analgesic effect at any dose. Pentobarbital, the most commonly used drug of this class, is considered a long acting anesthetic. Methohexital and Thiopental are considered short and ultra-short acting anesthetics and were more commonly used as induction agents in large animal species. Rapid anesthetic onset; provides a prolonged duration of surgical anesthesia; decades of use has characterized many research side effects; Pentobarbital is theactive drug in manufactured euthanasia solutions.

\section{Local anesthesia}

Local anesthesia block nerve conduction by inhibiting influx of sodium ions through ion-selective sodium channels in nerve membrane leading to impairment of the generation of action potential. The sodium channel itself is a specific receptor for local anesthetic molecules. Local anesthesia can be classified into topical or surface anesthesia and regional anesthesia. Topical anesthesia's are like $2 \%$ or $4 \%$ lignocaine $\mathrm{HCl}$ or other can be used for the relief of pain in abrasions or eczematous areas. Infiltration anesthesia applies to nerve ending of animals at the actual site of the operation to block nerve.

Linear infiltration: it is done on the line of the incision or just parallel to the line of the incision. The amount to be infiltrated is $1 \mathrm{ml} / \mathrm{cm}$ in small animals and $2 \mathrm{ml} / \mathrm{cm}$ in case of large animals. The anaesthetic is to be infiltrated into the subcutaneous area as well as into the muscles. The technique can be used for any type of the surgical operation like rumenotomy, cystotom.

Inverted ' $L$ ' or ' $T$ ' or inverted ' $V$ ' block: $2 \%$ Lignocaine $\mathrm{HCl}$ is injected into the tissues bordering the dorsocaudal aspect of the last rib and ventrolateral aspect of the lumbar transverse processes. Inverted ' $\mathrm{V}$ ' block technique is primarily used for teat surgery or management of accidental wounds of the limbs.

Field Block and Ring Block: It is the technique by which a wall of the local anaesthetic is formed around the site of operationThe volume used will depend on the size of the animal and the area to be blocked.

The common drugs which used in local anesthesia are listed as following:

Lidocaine: It has rapid onset of action, Duration of action is variable (depending on uptake) but will be around 1 hour without epinephrine, and 2 hours with epinephrine.

Bupivacaine: It has prolonged duration of action ( $8 \mathrm{hrs}$ ) when combined with epinephrine. It is therefore used whenever long action is required (post-op analgesia; prolonged surgery etc)

Mepivacaine: it is widely used in horse as it causes very little swelling ans edema in the area of injection, it lacks vasodilatory action. Onset of action is faster and reliability of block greater than with prilocaine.

Pirocaine: It has slower onset of action, and spreads less well compared to lidocaine. The unique ability of prilocaine to cause dose dependent methemoglobinemia limits its clinical usefulness. The main use is in the horse as it causes less swelling but great accuracy is needed when doing specific nerve blocks.

\section{Routes of Drug Administration}

Medications are administered to cattle by injection for a variety of reasons. For example, vaccines (biological) are injected to prevent disease, and antibiotics or anthelmintic may be injected to treat bacterial or parasitic infections, respectively. Other medications may be given by injection for supportive medical care, to relieve pain or to enhance production. Injection may be the best, or the only, route of administration for a particular medication [8].

The routes of drug administration in domestic animals are summarized as following form (Figure 1-3) $[8,12]$ : 
Oral administration: There are large numbers of pharmaceutical preparations available for oral administration. Solid dosage forms (powders, tablet, capsules, pills, etc.) and liquid dosage forms (syrups, emulsion, mixture, drench, electrolytes, etc.)

Parenteral administration: (IV, IM, SC, Id, epidural, subconjunctival): It refers to a drug administration by injection directly in to the tissue fluid or blood without having to cross the intestinal mucosa (Table 1).

Intravenous route (IV): Gives swift, effective and highly predictable blood concentration and allows rapid modification of dose and is used for emergency treatment. Jugular vein is the common route of drug administration in large animals (horse, cattle, sheep and goat) usually given through jugular vein, in pig-ear veins, in the dog and cat-cephalic veinand recurrent tarsal vein (Figure 1).

Intramuscular (IM) route: Absorption occurs either haematogenous or via lymphatic and is usually fairly rapid except for long acting preparation.

Subcutaneous (SC) route: Preferred when slow and continuous absorption of drug is required. The injected drug disperses through the loose connective tissues. They dissolve in tissue fluid before it can enter either capillaries or lymphatic.

Intradermal route (ID): Used for testing hypersensitivity test and for vaccination.

Epidural route: Refers to deposition of drug up on or outside the dura matter. E.g. Introduction of local anesthetics between the first and second coccygeal vertebra and lumbosacral to eliminate straining.

Subconjunctival: Disposition of a pharmaceutical preparation beneath the conjunctiva.

Topical or local application: It refers to external application

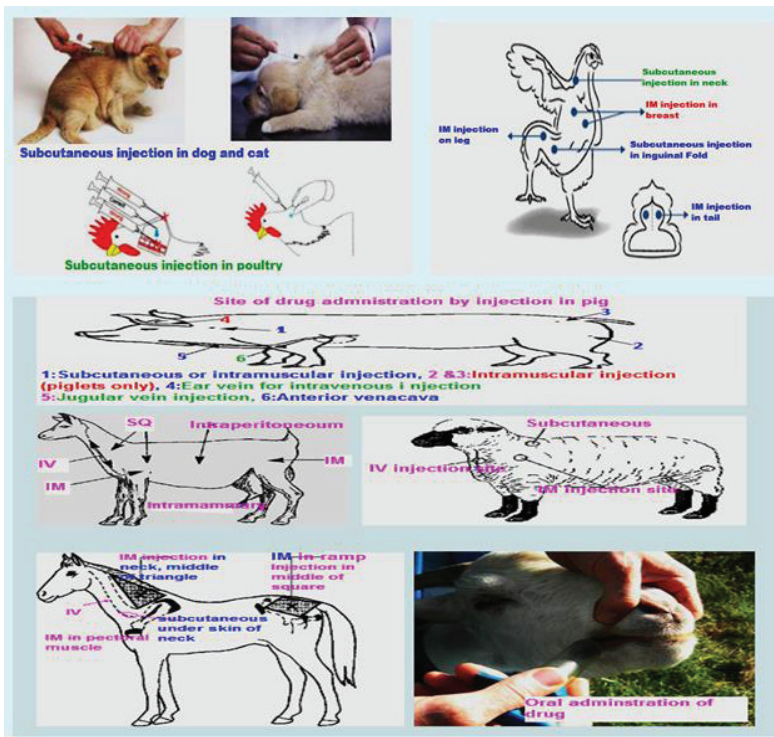

Figure 1: Route of drug administration site in domestic animals, cat, dog, poultry, pig, shoat and horse.

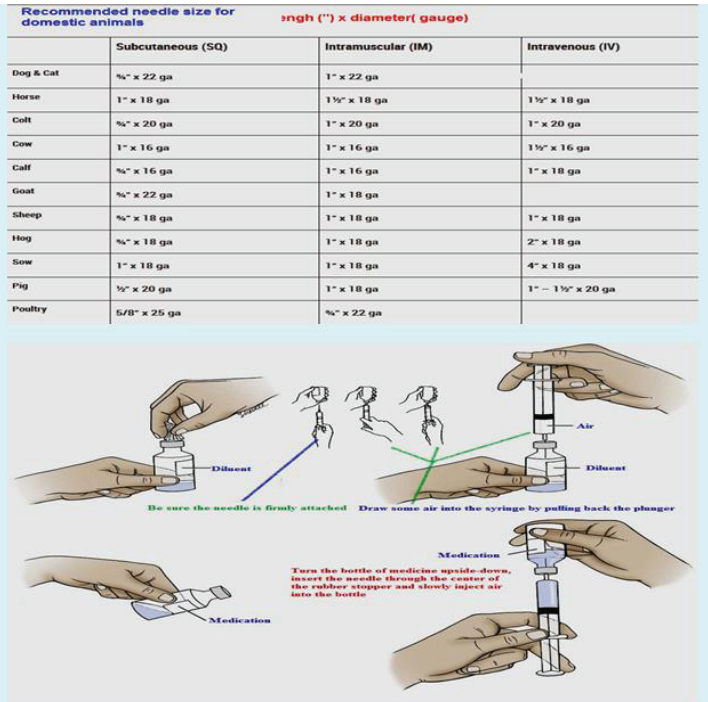

Figure 2: Types of needles and methods how to drawing ou of medication bottle.

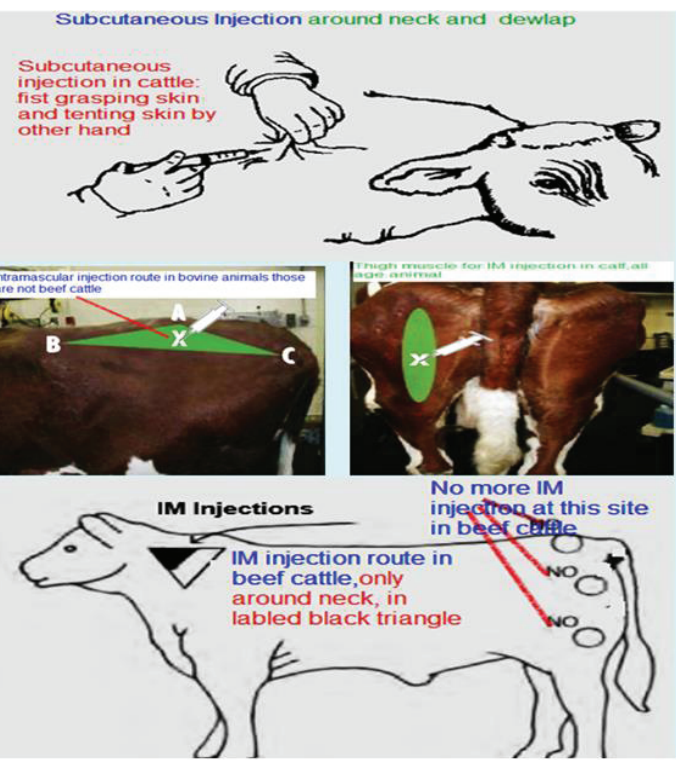

Figure 3: Parentral route of drug administration in bovine animals.

of drug to the body surface for localized action at accessible site, such as skin, eyes, body orifices, body cavity.

\section{Drug dose calculation}

If drugs are used incorrectly, disease organisms can build up resistance making drugs ineffective. This usually happens from under dosing or overdosing drugs. It is best to calculate the correct dosage based upon the weight of each animal determined by using a scale or estimated by using heart girth measurement $[1,10]$. Dose is the quantity of the drug to be administered at one time and expressed in $\mathrm{mg} / \mathrm{kg}$ or $\mathrm{IU} / \mathrm{kg}$.

Generall Equation for calculating and converting of the concentration of drugs.

*Dose required (Equals drug volume in $\mathrm{ml}$ or $\mathrm{cc}$ ) $=$ Animal weight $(\mathrm{kg}) \mathrm{x}$ dosage $(\mathrm{mg} / \mathrm{kg})$ divide by Concentration of drug $(\mathrm{mg} / \mathrm{ml})$. 
Table 1: Site of parenteral injection in domestic animals.

\begin{tabular}{|c|c|c|c|}
\hline Animals species & Intramuscular injection site & $\begin{array}{l}\text { Intravenous } \\
\text { injection site }\end{array}$ & Subcutaneous injection site \\
\hline Horse, Buffalo & $\begin{array}{l}\text { *Rump is avoided in horse it } \\
\text { may cause some sensitivity like } \\
\text { swelling, heat and pain. So that it } \\
\text { is difficult to drain abscess. } \\
\text { Therefore neck muscle is the } \\
\text { best site for Equine animals. } \\
\text { Thigh also possible. }\end{array}$ & Jugular vein & $\begin{array}{l}\text { Horses have very little loose skin } \\
\text { in which to give an SQ injection } \\
\text { compared to otherdomestic } \\
\text { species. Under the skin at the } \\
\text { side of the neck (due to horse } \\
\text { have skin in the fatty or loose } \\
\text { connective tissue layer which is } \\
\text { less sensitive to drug. }\end{array}$ \\
\hline Cattle, yak & $\begin{array}{l}\text { Rump, thigh (semimembranosus } \\
\text { and semitendinosus) }\end{array}$ & Jugular vein & $\begin{array}{l}\text { Under the skin at the side of the } \\
\text { neck, Dewlap. }\end{array}$ \\
\hline Sheep, Goat & Thigh & Jugular vein & $\begin{array}{l}\text { Behind the elbow or just over a } \\
\text { rib. Under the skin on the inside } \\
\text { of the hind leg. }\end{array}$ \\
\hline Dog, cat & Thigh & $\begin{array}{l}\text { Cephalic, } \\
\text { Saphenous veins }\end{array}$ & $\begin{array}{l}\text { Under Skin over the middle of the } \\
\text { back or just behind the } \\
\text { shoulders. }\end{array}$ \\
\hline Chicken & $\begin{array}{l}\text { Chest(breast muscle), Pectoral } \\
\text { muscle }\end{array}$ & Wing vein & $\begin{array}{l}\text { Under skin, after parting the } \\
\text { feathers on the breast. Under } \\
\text { skin at back of neckin small } \\
\text { chicks. }\end{array}$ \\
\hline Pig & Thigh & Ear vein & $\begin{array}{l}\text { Under skin inside the thigh for } \\
\text { small pig and Under skin at the } \\
\text { behind of the ear }\end{array}$ \\
\hline
\end{tabular}

*The unit conversion, $1 \mathrm{ml}$ (millilitre) = $1 \mathrm{cc}$ (cubic centimeter; $1 \mathrm{~kg}$ (Kilogram) $=2.2 \mathrm{Ibs}$ (pound) $; 1 \mathrm{~cm}=0.394$ inch and 1 inch $=2.54 \mathrm{~cm} ; 1$ foot $=0.3048 \mathrm{~cm}$ and $1 \mathrm{~cm}=0.033$

*Convert the concentration of a solution expressed in percent into $\mathrm{mg} / \mathrm{ml}$ : Multiply percent figure by 10 = given $\%$ x $10 \mathrm{mg} / \mathrm{ml}$.

*Percent solution $=$ Weight in gram $\mathrm{x} 100$ divide by the volume of solution in mls.

*Weight in grams $=$ Volume of solution in mls $\mathrm{x}$ percent solution divide by 100 .

Example: If one cow is presented to clinic, The Clinician Undergoes Clinical Examination and HePrescribed the Oxtetracycline $10 \%$. The cow weighs $350 \mathrm{~kg}$ and requires a daily injection of $10 \%$ drug in solution at the $10 \mathrm{mg} / \mathrm{kg}$ dose rate. Calculate the volume of the dose to be administered for Cow.

* Solution:

$10 \%$ solution $=10 \times 10 \mathrm{mg} / \mathrm{ml}=100 \mathrm{mg}$ in $1 \mathrm{ml}$.

$>$ Dosage rate $=10 \mathrm{mg} / \mathrm{kg}$

$>$ Dosage rate $\mathrm{x}$ body weight $=10 \mathrm{mg} / \mathrm{kg}$ x $350 \mathrm{~kg}=3500 \mathrm{mg}$

$>$ The volume of drug required $=3500 \mathrm{mg} / 100 \mathrm{mg} / \mathrm{ml}=35$ mls/ day

- Vets often use Latin abbreviations to denote how often the dog should receive the antibiotic during the day:

- SID: Once a day dosing

- BID: Twice a day dosing

- TID: Three times a daydosing

- QID: Four times a daydosing
- Stat: Immediate at that day

Method and procedure how to load a syringe during taking drug (Figure 2) [11]:

- Be sure the needle is firmly attached.

- Draw some air into the syringe by pulling back the plunger.

- Turn the bottle of medicine upside-down, insert the needle through the centre of the rubber stopper and slowly inject air into the bottle.

- Now draw the medicine into the syringe.

- Keep the bottle above the syringe so any air bubbles in the syringe go to the top.

- Push the plunger carefully so the air comes out.

- Now see if the right amount is in the syringe (the top of the plunger should be on the line for the proper dose).

Withdraw more medicine or squirt some back into the bottle until the right amount is in the syringe.

\section{References}

1. National Veterinary Drug Formulary (2013). Second Edition Department of Livestock, Ministry of Agriculture \& Forests. Website available at http://www. ncah.gov.bt/Downloads/File_3.pdf.

2. Tiwari, S., Mitkare, S. A. C. H. I. N., and Bhangale, P. (2014). Veterinary dosage forms: review. International Journal of Applied Pharmaceutics, 6(1), 20-29.

3. Holden-Dye, L., and Walker, R. J. (2007). Anthelmintic drugs. WormBook, 2 $1-13$.

4. Enejoh OS, Suleiman MM .2017. Anthelmintics and their Application in Veterinary Medicine Res Med Eng Sci. 2(3). RMES.000536. 2017

5. Aliu, Y.O (2007) Veterinary Pharmacology (1 st edition): 409-427; 448 - 462.

6. Boothes M. (2001). Veterinary Pharmacology and Therapeutics for small animals. Technicians $333-335$

7. Wanamaker B.P and Kathy L.M (2009). Applied Pharmacology for Veterinary

8. Griffin, Dicky D.; Smith, David R.; and Grotelueschen, Dale M., “G98-1351 Proper Injection Procedures for Cattle" (1998). HistoricalMaterials from University of Nebraska-Lincoln Extension. Paper 349

9. Duguma A (2016). Practical Manual on Veterinary Clinical Diagnostic Approach. J Vet Sci Technol 7: 337. doi:14.4172/2157-7579.1000337

10. Dawson, L., J. Allen and B. Olcott.2007. Meat Goat Herd Health Procedures and Prevention. In: T.A. Gipson, R.C. Merkel, K. Williams and T. Sahlu (Eds.). Meat Goat Production Handbook. Langston University. 65-96 pp.

11. Hadrill, D. (2002). Horse healthcare. A manual for animal health workers and owners.

12. Tiwari, S., Mitkare, S. A. C. H. I. N., and Bhangale, P. (2014). Veterinary dosage forms: review. International Journal of Applied Pharmaceutics, 6(1), 20-29

Copyright: (c) 2018 Serbessa TA. This is an open-access article distributed under the terms of the Creative Commons Attribution License, which permits unrestricted use distribution, and reproduction in any medium, provided the original author and source are credited. 